\title{
Feedback Menggunakan Telepon Genggam Terhadap Latihan Mandiri Mahasiswa: penelitian kualitatif
}

\author{
Ide Pustaka Setiawan \\ Laboratorium Keterampilan Medis, \\ Bagian Pendidikan Kedokteran, Fakultas Kedokteran UGM, Yogyakarta, Indonesia
}

\begin{abstract}
ABSTRACK
Background: Feedback is usually delivered face to face, in appropriate manner and appropriate time (Dent E Harden, 2005), from instructor to the students during skills training session. But bow the instructor gives feedback when the students conduct independent study? Could recording facility of students' mobile phone (handphone) solve this problem? Goals: The aims of this study are to understand whether or not mobile phone could be used to provide feedback toward students' independent study as well as to develop a process of giving feedback using mobile phone toward students' independent study.

Methods: This was qualitative study. All first year students academic year 2010/2011 $(n=400)$ were assigned to do independent study to practice communication skill, basic physical examination, vital sign examination toward 10 differently bealthy person in community. During independent study, students asked to record their skill using video recording facility within their own mobile phone. The recording file from mobile phone was then burnt to the CD. Both peers and instructors asked to watch the students' performance in VCD as well as to give written feedback which is equipped by structured questions. Survey as to feedback given to students toward both peers $(n=49)$ and skills lab instructor $(n=50)$ which are selected randomly was conducted. After receiving written feedback from both peers and instructors, students who perform in VCD were asked to make written reflection about feedback that is given to them. Result and Discussion: All data obtained from survey were compiled. Three coders were assigned to analize the data. They worked separately to look for the finding categories (open coding) assisted by atlas ti 6.0 software. Coders meet frequently to discuss the finding and achieve agreement. The study yielded the following results: 1) feedback on skills includes: communication aspect, physical examination and attitude, 2) feedback on quality of recording includes feedback on: video, recording tools, actor and setting, 3) Students' reflection said that the feedback is useful; 4) There are suggestions to improve the recording result

Conclusion: 1) Mobile phone could be used to provide feedback toward students' independent study, 2) Technical things should be noticed in order to get better quality of recording
\end{abstract}

Keywords: Feedback, mobile phone, handphone, independent study, video learning

\section{ABSTRAK}

Latar Belakang: Feedback biasanya diberikan secara tatap muka oleh instruktur kepada mahasiswa dengan cara dan waktu yang tepat (Dent \& Harden, 2005). Namun bagaimana pemberian feedback pada saat mahasiswa melakukan latihan mandiri? Apakah fasilitas rekam video pada telepon genggam (handphone) dapat mengatasi permasalahan tersebut?

Tujuan: Tujuan dari penelitian ini adalah untuk mengetahui apakah handphone dapat digunakan untuk memberikan feedback terhadap latihan mandiri mahasiswa serta untuk mengembangkan proses pemberian feedback menggunakan handphone terhadap latihan mandiri mahasiswa

Metode: Penelitian ini adalah penelitian kualitatif. Semua mahasiswa tahun pertama tahun akademik 2010/2011 $(n=400)$ ditugaskan melakukan belajar mandiri untuk mempraktikkan keterampilan komunikasi, pemeriksaan fisik dasar dan pemeriksaan tanda vital kepada 10 orang di komunitas. Pada saat belajar mandiri, mahasiswa

Korespondensi: idepustaka@ugm.ac.id 
diminta merekam keterampilan mereka menggunakan handphone mereka sendiri. File rekaman tersebut kemudian di-burnt ke dalam CD. Peers dan instruktur kemudian diminta untuk melihat keterampilan mahasiswa dalam VCD termasuk memberikan feedback secara tertulis yang dipandu dengan beberapa pertanyaan terstruktur. Survey tentang feedback yang diberikan kepada mahasiswa, dilakukan kepada peers $(\mathrm{n}=49)$ dan instruktur $(\mathrm{n}=50)$ yang dipilih secara acak. Setelah menerima feedback tertulis dari peers dan instruktur, mahasiswa yang direkam dalam VCD diminta untuk menuliskan refleksi secara tertulis tentang feedback yang diberikan kepada mereka.

Hasil dan Pembahasan: Semua data survey dikompilasi menjadi satu. Tiga orang pengkoding ditugaskan untuk melakukan analisis data tersebut. Pengkoding bekerja secara individu untuk menemukan kategori-kategori temuan secara koding terbuka (open coding) dengan bantuan software atlas ti 6.0). Pengkoding bertemu beberapa kali untuk mendiskusikan temuan-temuan tersebut hingga mencapai kesepakatan. Diperoleh hasil sebagai berikut: 1) feedback atas penampilan keterampilan yang meliputi aspek: komunikasi, pemeriksaan serta attitude, 2) feedback atas kualitas rekaman yang meliputi feedback terhadap: video, alat perekam, pemeran serta setting, 3) refleksi mahasiswa setelah mendapat feedback yang menyatakan bahwa feedback yang diberikan sangat bermanfaat, serta 4) saran perbaikan

Kesimpulan: 1) Handphone dapat digunakan untuk memberikan feedback terhadap latihan mandiri mahasiswa, 2) Hal-hal teknis perlu diperhatikan agar video hasil rekaman telepon genggam mempunyai kualitas yang optimal sehingga mempermudah pemberian feedback.

Kata Kunci: Feedback, telepon genggam, handphone, latihan mandiri, video learning

\section{PENDAHULUAN}

Keterampilan medis adalah salah satu unsur dalam mencapai sebuah kompetensi. ${ }^{1}$ Dalam proses belajar keterampilan medis mahasiswa dianjurkan melakukan latihan sesering mungkin untuk dapat menguasai keterampilan dengan baik. Mahasiswa dianjurkan belajar keterampilan medis dimanapun dan kapanpun mereka berada. Mahasiswa dapat belajar keterampilan medis di laboratorium keterampilan medis ataupun latihan secara mandiri di masyarakat. ${ }^{2}$

Belajar keterampilan medis sangatlah berbeda dengan belajar pengetahuan kognisi. Belajar keterampilan medis membutuhkan kehadiran instruktur sebagai role model dan pemberi umpan balik (feedback) atas penampilan keterampilan yang sedang dipelajari. Sedangkan belajar pengetahuan kognisi dapat dilakukan mahasiswa secara mandiri tanpa bimbingan khusus dari seorang instruktur. Sehingga dapat dikatakan kehadiran instruktur dalam latihan keterampilan medis adalah sangat mutlak diperlukan.,

Pada saat latihan keterampilan medis di skills lab (tatap muka dengan instruktur) adalah sangat mudah bagi seorang instruktur dalam mengamati dan memberikan umpan balik (feedback) terhadap penampilan mahasiswa dalam berlatih keterampilan medis. Dengan feedback yang diberikan oleh seorang instruktur, mahasiswa menjadi tahu dan paham atas kemampuan mereka. Mahasiswa mengetahui hal apa saja yang sudah mereka lakukan dengan baik dan sebaliknya mahasiwa mengetahui hal apa saja yang masih perlu ditingkatkan agar keterampilan medis yang mereka lakukan menjadi sempurna.

Namun bagaimana pemberian feedback terhadap latihan keterampilan medis mandiri yang dilakukan oleh mahasiswa? Untuk menghadirkan seorang instruktur sebagai pendamping latihan mandiri mahasiswa di masyarakat adalah sangat mahal dalam hal waktu dan biaya. Hal ini kurang feaseable mengingat latihan mandiri mahasiswa adalah sebuah latihan yang tidak terjadwal, mahasiswa bebas melakukan latihan mandiri kapanpun dan dimanapun mereka berada. Sedangkan untuk mendatangkan seorang instruktur sebagai pemberi feedback membutuhkan penjadwalan sebelumnya.

Video learning bisa menjadi solusi permasalahan tersebut. Video merupakan salah satu sarana untuk memberikan feedback. ${ }^{5}$ Sebuah studi memaparkan manfaat video sebagai media ajar sebagai berikut ${ }^{8}$ :

1. Video dapat membantu mahasiswa dalam memvisualisasikan bagaimana suatu proses terjadi 
2. Video dapat menampilkan informasi yang lebih detail dibandingkan dengan penyampaian informasi melalui tulisan ataupun gambar yang tidak bergerak

3. Video dapat menarik perhatian mahasiswa, memotivasi mereka serta dapat lebih memahamkan mereka terhadap topik yang sedang dipelajari

4. Video dapat memberikan contoh yang nyata bagi mahasiswa, sehingga mahasiswa akan lebih mudah membayangkan situasi nyata yang terjadi.

5. Video dapat menstimulasi diskusi

6. Video dapat menyediakan informasi yang cocok bagi semua mahasiswa dengan gaya belajar apapun, terutama mahasiswa yang mempunyai gaya pembelajaran visual.

Namun video learning selama ini membutuhkan sarana dan prasarana yang canggih, mahal dan membutuhkan tenaga tertentu untuk mengoperasikannya. ${ }^{6}$ Sehingga video learning yang selama ini digunakan belum bisa mengatasi masalah bagaimana pemberian feedback terhadap latihan keterampilan medis mandiri mahasiswa di masyarakat.

Dewasa ini jumlah pemilik dan pengguna telepon genggam (handphone) semakin meningkat. Data dari ITU (International Telecommunication Union: Persatuan Telekomunikasi Internasional), menyatakan bahwa separuh penduduk dunia (3.3 milyar jiwa) telah memiliki telepon genggam pada tahun 2007. Indonesia sendiri menduduki peringkat ke-6 dalam jumlah pemilik telepon genggam terbanyak di dunia yaitu sebesar 116 juta pengguna. Fasilitas internet menjadi alasan utama bagi pengguna dalam membeli telepon genggam. Pengguna dapat menikmati telepon genggam melalui fasilitas internet untuk berselancar di dunia maya selain menggunakannya sebagai alat komunikasi dan memanfaatkan fasilitas yang ada di telepon genggam lainnya seperti fasilitas permainan dan kamera untuk mengambil foto bahkan merekam video. ${ }^{7}$ Fasilitas rekam video yang ada di telepon genggam sering digunakan untuk merekam aktivitas pribadi pemilik. Perlu difikirkan pemanfaatan fasilitas rekam video untuk proses pendidikan terutama pemberian feedback dengan harapan dapat mengatasi masalah yang ada.

Apakah fasilitas rekam video pada telepon genggam (handphone) dapat mengatasi permasalahan yang ada?
Untuk itu tujuan dari penelitian ini adalah untuk mengetahui apakah handphone dapat digunakan untuk memberikan feedback terhadap latihan mandiri mahasiswa serta untuk mengembangkan proses pemberian feedback menggunakan handphone terhadap latihan mandiri mahasiswa.

\section{METODE}

\section{Pengumpulan Data}

Penelitian ini adalah penelitian kualitatif. Semua mahasiswa tahun pertama tahun akademik 2010/2011 $(n=400)$ ditugaskan melakukan belajar mandiri untuk mempraktikkan keterampilan komunikasi, pemeriksaan fisik dasar dan pemeriksaan tanda vital kepada 10 orang di komunitas. Pada saat belajar mandiri, mahasiswa diminta merekam keterampilan mereka menggunakan handphone mereka sendiri. File rekaman tersebut kemudian di-burnt ke dalam CD. Peers dan instruktur kemudian diminta untuk melihat keterampilan mahasiswa dalam VCD termasuk memberikan feedback secara tertulis yang dipandu dengan beberapa pertanyaan terstruktur. Survey tentang feedback yang diberikan kepada mahasiswa, dilakukan kepada peers $(n=49)$ dan instruktur $(n=50)$ yang dipilih secara acak. Setelah menerima feedback tertulis dari peers dan instruktur, mahasiswa yang direkam dalam VCD diminta untuk menuliskan refleksi secara tertulis tentang feedback yang diberikan kepada mereka.

\section{Analisis Data}

Semua data survey dikompilasi menjadi satu. Tiga orang pengkoding ditugaskan untuk melakukan analisis data tersebut. Pengkoding bekerja secara individu untuk menemukan kategori-kategori temuan secara koding terbuka (open coding) dengan bantuan software atlas ti 6.0. Selanjutnya pengkoding bertemu beberapa kali untuk mendiskusikan temuan-temuan mereka hingga mencapai kesepakatan.

\section{HASIL DAN PEMBAHASAN}

\section{Feedback atas penampilan keterampilan}

Melalui rekaman video peer dapat memberikan feedback yang meliputi:

1. Perkenalan diri

2. Jabat tangan 
3. Komunikasi interpersonal

4. Informed consent

5. Cuci tangan

6. Persiapan alat

7. Persiapan teori tentang vital sign

8. Pemeriksaan vital sign (pemeriksaan tekanan darah, nadi, respirasi dan temperatur)

9. Pelaporan hasil pemeriksaan

10. Edukasi

11. Attitude (penggunaan jas praktikum, percaya diri, posisi pemeriksaan, senyum)

Melalui rekaman video handphone instruktur dapat memberikan feedback kepada mahasiswa yang meliputi:

1. Perkenalan diri

2. Komunikasi interpersonal

3. Informed consent

4. Cuci tangan

5. Persiapan alat

6. Pemeriksaan vital sign (pemeriksaan tekanan darah, nadi, respirasi dan temperatur)

7. Melaporkan hasil pemeriksaan

8. Edukasi

9. Attitude (penampilan rapi, ramah, senyum, sopan)

Dari beberapa aspek feedback di atas secara garis besar dapat di diringkasi menjadi 3 aspek utama yaitu:

1. Komunikasi, yang meliputi:

- Perkenalan diri dan jabat tangan

- Komunikasi interpersonal

- Persiapan teori

- Informed consent

- Pelaporan hasil pemeriksaan

- Edukasi

2. Pemeriksaan

- Cuci tangan

- Persiapan alat

- Pemeriksaan vital sign

3. Attitude

\section{Feedback atas kualitas rekaman}

Feedback peer terhadap kualitas rekaman video dari handphone meliputi:

1. Sudut pengambilan gambar

2. kestabilan gambar (adanya goyangan)

3. Kualitas suara (keras, kurang jelas, suara tidak ada)
4. Kualitas alat perekam

5. Kualitas gambar (pencahayaan kurang, gambar terputus-putus, gambar kabur, pixel terlalu kecil)

6. Format untuk melihat video tidak cocok

7. Gangguan suara luar

8. Tidak natural jika video diedit

9. Kesan (penampilan) dibuat-buat

Feedback instruktur terhadap kualitas rekaman video dari handphone meliputi:

1. Sudut pengambilan gambar (jarak perekaman)

2. Fokus perekaman

3. Kestabilan gambar (goyangan)

4. Kualitas suara (keras, kurang jelas, suara tidak ada)

5. Kualitas gambar (gambar cukup bagus, namun ada yang kurang terang, gambar terputus-putus, gambar kabur, pixel terlalu kecil)

6. Gangguan suara luar (back sound/back song)

Secara garis besar feedback atas kualitas rekaman video dapat diringkas menjadi:

1. Video

- Sudut pengambilan gambar (jarak perekaman)

- Fokus perekaman

- Kestabilan gambar (goyangan)

2. Alat perekam

- Kualitas suara (keras, kurang jelas, suara tidak ada)

- Kualitas gambar (gambar cukup bagus, namun ada yang kurang terang, gambar terputus-putus, gambar kabur, pixel terlalu kecil)

- Format untuk melihat video tidak cocok

3. Pemeran

- Tidak natural jika video diedit

- Kesan (penampilan) dibuat-buat

4. Setting

- Ganguan suara luar (back sound/back song)

\section{Refleksi mahasiswa setelah mendapat feedback}

Meskipun dengan segala keterbatasan rekaman video semua mahasiswa menyatakan umpan balik atau feedback yang diberikan oleh peer adalah sangat bermanfaat:

"Feedbacknya sangat bermanfaat. Dengan feedback yang diberikan, saya dapat mengetahui kelebihan dan 
kekurangan yang saya lakukan saat melakukan vital sign $\mathcal{E}$ membangun hubungan interpersonal dengan probandus. Sehingga yang sudah baik dapat saya pertahankan $\mathfrak{G}$ yang masih kurang dapat saya perbaiki agar menjadi lebih baik"

\section{Saran perbaikan}

Selanjutnya instruktur dan peer memberikan saran untuk memperbaiki rekaman video meliputi:

1. Pada saat tertentu gambar perlu di zoom supaya tidak monoton

2. Perlu menggunakan alat perekam (kamera handphone) yang lebih baik

3. Perlu menggunakan alat bantu microfon yang lebih baik

4. Perlu penggunaan tripod agar gambar stabil dan tidak goyang

5. Perlu diperhatikan pencahayaan

6. Tidak perlu menggunakan back sound agar tidak mengganggu pemeriksaan

7. Perekaman dilakukan di tempat yang lebih tenang

\section{Feedback atas penampilan keterampilan}

Baik peer maupun instruktur secara detail dapat memberikan feedback atas penampilan keterampilan mahasiswa dalam berlatih di masyarakat. Feedback yang diberikan meliputi semua aspek yang terkait dalam keterampilan pemeriksaan vital sign, mulai dari perkenalan diri sampai pada edukasi secara sekuensial. Video dapat menampilkan informasi yang lebih detail dibandingkan dengan penyampaian informasi melalui tulisan ataupun gambar yang tidak bergerak. ${ }^{8}$

Titik berat dari feeback tersebut adalah terutama pada aspek komunikasi, pemeriksaan, serta attitude. Sebuah studi menyebutkan bahwa di skills lab rekaman video sangat cocok dalam menilai keterampilan komunikasi namun kurang ideal bila dimanfaatkan dalam menilai keterampilan fisik dan keterampilan prosedural karena adanya keterbatasan lapang pandang dalam merekam. ${ }^{9}$ Di Inggris, adalah suatu hal yang wajib bagi mahasiswa postgraduate family medicine untuk mempunyai rekaman video atas penampilan keterampilan komunikasi mereka, sebelum mereka ujian akhir. ${ }^{10}$
Hal di atas berarti keterampilan komunikasi bisa dinilai dari rekaman video. Tidak hanya itu, komunikasi non verbal juga bisa dipelajari dari rekaman video. ${ }^{10}$

Seorang penulis menyebutkan bahwa dengan video, manusia dapat menangkap informasi sebesar 55\% dari keseluruhan informasi yang disampaikan kepadanya. Hal ini lebih bagus apabila dibandingkan dengan manusia menangkap informasi melalui pendengaran/audio. Melalui intonasi suara manusia dapat menangkap informasi sebesar 38\%, sedangkan melalui tulisan manusia hanya dapat menangkap informasi sebesar 7\%. Apabila ketiga aspek tersebut digabungkan (video, audio dan tulisan), maka informasi yang dapat ditangkap oleh manusia menjadi semakin besar. ${ }^{11}$ Tak heran jika feedback secara detail dapat diberikan dari melihat video.

\section{Feeback atas kualitas rekaman}

Feedback video meliputi, sudut pengambilan gambar (jarak perekaman), fokus perekaman, serta kestabilan gambar (goyangan). Beberapa tips tentang kualitas video diantaranya. ${ }^{13}$

1. mengambil rekaman video dengan cara sedekat mungkin dengan obyek apabila handphone yang digunakan tidak memiliki mode zoom.

2. Posisi pengambilan rekaman ditahan jangan sampai bergoyang atau sering berpindah posisi karena nanti akan menghasilkan gambar rekaman yang kurang bagus untuk dinikmati.

3. Jangan membelakangi sinar matahari, usahakan mencari tempat penerangan yang cukup.

Mungkin karena inilah ada pendapat yang mengatakan feedback terhadap video lebih jelas pada keterampilan komunikasi daripada keterampilan pemeriksaan fisik. Di skills lab rekaman video sangat cocok dalam menilai keterampilan komunikasi namun kurang ideal bila dimanfaatkan dalam menilai keterampilan fisik dan keterampilan prosedural karena adanya keterbatasan lapang pandang dalam merekam. ${ }^{9}$

Terhadap alat perekam sendiri diperlukan alat perekam dengan resolusi yang baik. Resolusi ini sangat mempengaruhi kualitas video. Kamera dengan resolusi yang kecil akan menghasilkan gambar yang tidak sesuai dengan ukuran aslinya dan menjadi pecah. Perlu 
diperhatikan juga kamera digital dengan kualitas rekam video yang mempunyai frame per second (FPS) yang tinggi . FPS yang rendah akan menyebabkan hasil rekaman video menjadi terputus-putus. Kamera video yang paling sederhana memiliki fps 15 , hasilnya masih patah-patah. Sedangkan fps 25 sudah cukup untuk dapat diikuti mata tanpa kelihatan terputus-putus dengan budget yang paling sedikit. ${ }^{14}$

Adanya kemudahan mengedit video membuat rekaman mahasiswa menjadi tidak natural. Penggunaan rekaman video menjadi sangat dibutuhkan di skills lab karena, rekaman video dapat dengan mudah diedit, diberikan penilaian, didiskusikan dan dianalisis oleh siapa saja, di mana saja dan kapan saja. ${ }^{5}$

\section{Refleksi mahasiswa setelah mendapat feedback}

Semua mahasiswa merasakan feedback yang bermanfaat, meskipun feedback diberikan setelah melihat rekaman video dengan segala keterbatasan yang membangun akan meningkatkan kompetensi mahasiswa. ${ }^{12}$

\section{Saran Perbaikan}

Saran perbaikan terhadap rekaman video meliputi. ${ }^{13}$

1. Pada saat tertentu gambar perlu di zoom supaya tidak monoton

Namun perlu hati-hati jangan terlalu sering zoom in dan zoom out agar tidak membuat pusing orang yang melihat video

2. Perlu menggunakan alat perekam (kamera handphone) yang lebih baik

Perlu diperhatikan alat perekam dengan resolusi yang tinggi dan FPS yang tinggi. ${ }^{14}$

3. Perlu menggunakan alat bantu mikrofon yang lebih baik

4. Perlu penggunaan tripot agar gambar stabil dan tidak goyang

Tripot memudahkan pengambilan angel di berbagai tempat, mengatasi getaran tangan sehingga menghasilkan ketenangan gambar.

5. Perlu diperhatikan pencahayaan

Untuk menunjang hasil video supaya lebih menarik diperlukan beberapa tambahan seperti Tripot, lampu tambahan, dan beberapa pemantul cahaya seperti stereofoam.
6. Tidak perlu menggunakan back sound agar tidak mengganggu pemeriksaan

7. Perekaman dilakukan di tempat yang lebih tenang

\section{KESIMPULAN}

Kesimpulan yang dapat ditarik adalah sebagai berikut:

1. Handphone dapat digunakan untuk memberikan feedback terhadap latihan mandiri mahasiswa

2. Hal-hal teknis perlu diperhatikan agar video hasil rekaman telepon genggam mempunyai kualitas yang optimal sehingga mempermudah pemberian feedback

\section{DAFTAR PUSTAKA}

1. IMC. Indonesian doctor competence standard. Jakarta: Indonesian Medical Council. 2006.

2. Widyandana, Majoor G, Scherpbier A. Transfer of medical student's clinical skills learned in a clinical laboratory to the care of real patients in the clinical setting: the challenges and suggestions of students in a developing country. Educ for Health; 2010;23(3):339.

3. Duvivier RJ, Dalen JV, Vleuten CPMVD, \& Scherpbier AJJA. Teacher perceptions of desired qualities, competencies and strategies for clinical skills teachers. Medical Teacher; 2006; 99999(1).

4. Suryadi E. Education in skills laboratory. Yogyakarta: Faculty of Medicine Universitas Gadjah Mada; 2008.

5. Adamo G, \& Dent JA. Teaching in the clinical skills centre. Dent JA \& Harden RM (Eds.), A practical guide for medical teachers. Dundee: Elsevier; 2005.

6. Setiawan. Laporan skill lab. FK UGM. Yogyakarta; 2008.

7. Anonim. Statistik pengguna handphone di Indonesia. 2010. From http://www.amipulsa.web.id/2010/10/ statistik-pengguna-handphone-indonesia.html

8. Maniar, N. The effect of mobile phone screen size on video based learning. Journal of software; 2008; 3(4):51-61.

9. Smith SR. Outcome-based curriculum. In Dent JA $\&$ Harden RM (Eds). A practical guide for medical teachers. Dundee: Elsevier; 2005.

10. Snadden D \& Ker JS. Communication skills. In Dent JA \& Harden RM (Eds). A practical guide for medical teachers. Dundee: Elsevier. 2005

11. Grover S. Benefits of video based e-learning; 2007. From http://shalinigrover.blogspot.com/2007/07/ benefits-of-video-based-e-learning.html 
12. Claramita M, Nirwati H. Constructive feedback during I.V line insertion of skills training of second year medical students in FM UGM, a grantee from DUE-LIKE project, Universitas Gadjah Mada, Yogyakarta. 2006.
13. http://www.boyolalikab.go.id/?art=detail\&id=34

14. http://tokokomputer007.com/ kamera-video

15. http://www.infogue.com/viewstory/2011/01/25/ tips_cara_merekam_video_dengan_hp_handphone/ ?url=http://agusray.blogspot.com/2011/01/tipscara-merekam-video-dengan-hp.html 